\title{
ASSESSMENT OF BIG CATS ABUNDANCE AND DISTRIBUTION IN SENGWA WILDLIFE RESEARCH AREA (SWRA): AN ANALYSIS OF MULTIPLE METHODS
}

\section{Innocent Mahakata}

Department of Terrestrial Ecology, Zimbabwe Parks and Wildlife Management Authority, Sengwa Wildlife Research Institute, Bag 6002, Gokwe.

Email: mahakatainnocent@gmail.com

Cite this article:

Innocent Mahakata (2021), Assessment of Big Cats Abundance and Distribution in Sengwa Wildlife Research Area (SWRA): An Analysis of Multiple Methods. African Journal of Environment and Natural Science Research 4(3), 108-120. DOI: 10.52589/AJENSRIYMVCHC9.

\section{Manuscript History \\ Received: 30 June 2021 \\ Accepted: 28 July 2021 \\ Published: 3 Oct 2021}

Copyright $(9) 2020$ The Author(s). This is an Open Access article distributed under the terms of Creative Commons AttributionNonCommercial-NoDerivatives 4.0 International (CC BY-NC-ND 4.0 ), which permits anyone to share, use, reproduce and redistribute in any medium, provided the original author and source are credited.
ABSTRACT: Large carnivores are considered key species and their presence signify health of the ecosystem. Mostly used methods to establish big cats abundance and spatial distribution in SWRA consist of spoor survey, individual observations, analysis of patrol data and interviews with safari operators. In this study, four methods were used to establish current abundance and distribution of big cats in Sengwa and to find advantages and disadvantage for each method used. To do this, spoor survey along twelve transects were done between $13^{\text {th }}$ to $20^{\text {th }}$ April 2020. Oral interviews with local professional hunters and park managers was done between $1^{\text {st }}$ and $10^{\text {th }}$ April 2020, whilst analysis of patrol reports from January 2018 to December 2019 were also done. Descriptive statistics was used for analysis of interview data. For other three methods, data were summarised in excel and quantitatively analysed. Mapping of spatial distribution of big cats from secondary data and spoor surveys were done in QGIS software. Five lion spoors and twenty-one leopard spoors were recorded during spoor survey. Two individual leopards and zero lions were also recorded. Lion spoors were mostly recorded along river valleys while leopard spoors were recorded in different habitats and terrain. Future related studies should focus on use of other survey design and combination of methods such as radio calls and camera traps as well as use of GPS enabled collars for monitoring and estimating abundance.

KEYWORDS: Big cats, Patrol reports, Spoor survey, Lions, Leopards, SWRA. 


\section{INTRODUCTION}

The lion (Panthera Leo) and Leopard (Panthera Pardus), (thereafter big cats in this paper) are a potent cultural symbol of Africa and an important indicator of an area's wilderness qualities and health (International Union for Conservation of Nature-IUCN, 2018). Big cats are also a key species for trophy hunting and research. Lack of scientifically proven data on abundance and spatial distribution threatens their future survival and management decisions on efforts to conserve them.

\section{LITERATURE}

In Africa, the remaining populations are often geographically isolated from one another, which can lead to inbreeding, and consequently, reduced genetic diversity (Lion Gurdian annual report 2013, Bauer et al, 2001). The IUCN consider big cats as vulnerable species. Despite their perceived decline in most parts of southern africa, the population of big cats in SWRA, is viewed as stable with population estimated between five and eight since 2010 (Zimbabwe Parks and Wildlife Authority Reports, 2016) for lions whilst leopards are estimated to be above ten. However, Trouwborst, et al (2019), highlighted that predator populations in the Sebungwe Region appear to be heavily impacted by anthropogenic threats, with lion and spotted hyena populations severely depressed and with relatively low leopard populations.

Zimbabwe is one of the few big cats range states in Africa, where its protected areas (PAs) hold viable big cats' populations. In some parts of Africa, big cats have been completely wiped out through uncontrolled hunting, revenge killings and habitat loss among other factors with the only record to indicate their existence in the past now left as anecdotal evidence especially in lions-(Lindsey et al 2012; Ferreira 2010). Much of the estimation is based on different methods applied from one area to another. Large cats surveys had been done in Hwange National Park (HNP) and Matetsi Safari Area (MSA) in northwest Matabeleland, Mana Pools (MNP), Gonarezhou National Park (GNP) and Matusadona national park in the Zambezi Valley (Loveridge, 2002, Purchase, 2002, Monks, 2005), and the Save Valley Conservancy (Groom, 2010), with different methods used in these areas such as use of spoor counts in GNP (Groom et at., 2017) and camera traps in MNP and HNP (National Leopard survey, 2019), whilst in SWRA, camera traps were used in 2019 but limited along the northern boundary.

In light of evidence from all the main range countries, the carnivores' populations have been undergoing decline in both range and numbers, often an accelerating decline, during the past two decades. In the early 1990s, IUCN/SSC Cat Specialist Group members made educated guesstimates of 30,000 to 100,000 for the African lion population (Nowell, 1996) with leopard population remaining uncertain. Ferreras and Cousins, (1996) predicted 18,600 lions to occur in PAs in the mid-1990s in Africa using data from guesstimates. The IUCN/SSC Cat Specialist Group estimated a decline in the African lion population for the 2004 IUCN Red List of Threatened Species for lions, this was probably an underestimate as not all PAs inhabited by big cats at that time were represented. In Zimbabwe, the lion population was estimated to be between 1,000-1,700 animals in 2002 (Chardonnet, 2002, Van Der Merwe and Bauer, 2004) with a current range of $60,000-90,000 \mathrm{~km}^{2}$ compared to their distribution over approximately $250,000 \mathrm{~km}^{2}$ in the early sixties (Smithers 1983). The national leopard population size and the species distribution in Zimbabwe are not known and there remain some parts of Zimbabwe 
where the conservation status of leopards is poorly understood (Lindsey and Mandisodza, 2012).

The leopard (Panthera pardus) was globally red-listed as 'vulnerable' in 2016, following a 'least concern' listing in 2002 and a 'near threatened' listing in 2008 (Henschel, et al, 2008). Many of the nine leopard subspecies are 'endangered' or 'critically endangered'. (Trouwborst, et al 2019). The ranges of some subspecies were reported to have collapsed, with leopards disappearing from $98 \%$ of their former range. In Zimbabwe, results from camera-trap surveys undertaken at 31 sites across the country in 2013-2017 by the South African Leopard Monitoring Project suggest an annual $8 \%$ decline of the national population (Trouwborst, et al 2019).

Several conventions and principles seeks to protect big cats through protecting the species or the habitats they occupy. The Precautionary Principle 15 which was specifically devised to guide decision making in the face of uncertainty provides a fundamental policy basis to anticipate, avoid and mitigate threats to environment and species while the Convention on Biodiversity (CBD) National Biodiversity Strategy Action Plan (Strategy 1) of Zimbabwe, also seeks to encourage relevant authorities in the wildlife industry to develop a comprehensive and elaborate biodiversity inventory and monitoring programmes for all species of flora and fauna. Strategy 9 of CBD encourages development and implementation of appropriate research and extension approaches in biodiversity conservation and sustainable use. Hence, Park managers and ecologists needs data on current population size and distribution of big cats in SWRA to have a baseline information for their future protection and sustainable utilisation.

In SWRA, lack of reliability on methods currently utilised in different areas makes it difficult to come up with exact figures for proper estimate of big cats. Therefore the study was undertaken for a number of reasons: (i) Resolving the conflicting population estimates by wildlife practitioners has been identified as the third priority for large cats' conservation by The World Conservation Union (IUCN, CAT SG. 2004). (ii) Wildlife practitioners need correct information for big cats monitoring and conservation. Furthermore, the African large cats are considered as vulnerable on the red data book list of world endangered species (IUCN 2004), and therefore these animals require comprehensive monitoring of population trends and distribution through triangulation of methods and data sources. Zimbabwe Strategy and Action Plan of 2006 for the protection of lions, sets the stage for sharing of experiences between stakeholders to create a better environment for wildlife practitioners and local communities for the conservation of big cats. Therefore, the study aimed to estimate big cat abundance and distribution in SWRA and analyse the strength and weakness of each method used to collect data.

\section{Methodology}

\section{Study Area}

The survey was carried out in SWRA, situated at the southern end of the Chirisa Safari Area $\left(18^{0} 10^{\mathrm{I}} \mathrm{S}, 28^{0} 14^{1}\right)$ in Gokwe South District, north-west Zimbabwe. Covering an area of 343 $\mathrm{km}^{2}$, the SWRA was set aside in 1965 for long term wildlife and ecological researches. The surface geology of the SWRA comprises of the Lower and Upper Karoo age. The geological formations of the study area have been dissected by the three north flowing rivers which are 
Lutope Manyoni and Sengwa River. SWRA is a semi-arid ecosystem with low and irregular rainfall and have three seasons which are; cool dry season (April to July), hot dry season (August to October) and hot wet season (November to March). A variety of vegetation types consisting of 16 types have been described and mapped, dominated by Colophospemum mopane, Acacia, miombo woodlands and the riverine vegetation. SWRA is a rich haven of fauna ranging from the mega to meso-herbivores and from the iconic big cats to the vulnerable brown hyena. The area remain one of the few parks in the Sebungwe Region that still holds high densities of a variety of mammals, birds, reptiles and amphibians that are a source of prey for carnivore species and attracts trophy hunters.

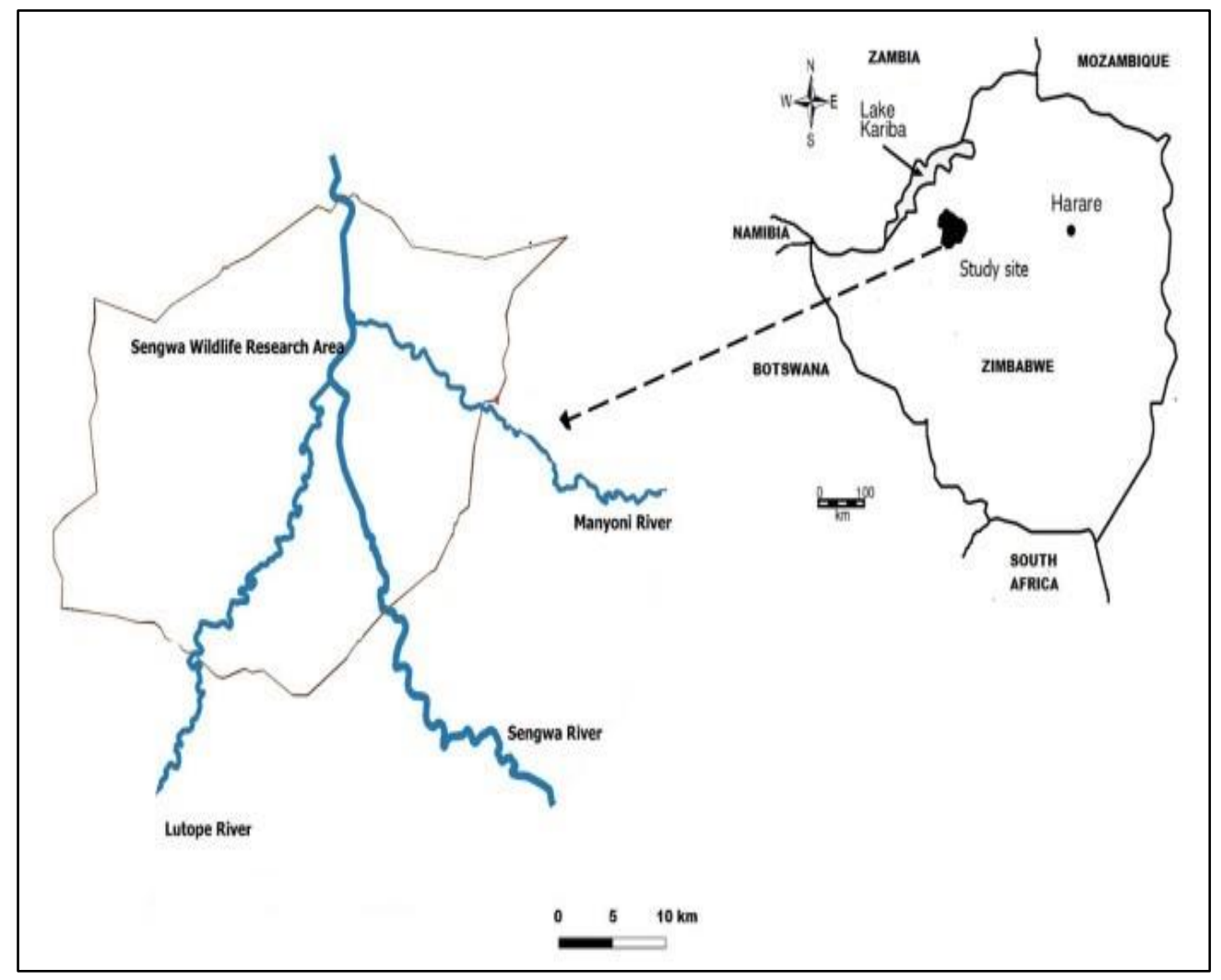

Figure 1: Map of study area.

\section{Study approach.}

In this study, I sought to identify big cats abundance and distribution in SWRA, and analyse the methods used in data collection as they were applied during data collection.

The methodology chosen in this survey follows similar methods used by Chardonnet (2002), Bauer and Van Der Merwe (2004) and Monks (2005) on informed guess and secondary data when they were estimating lion population size and ranges in African lion range areas and in Mana-Pools respectively. Spoor count and individual observation methods follows similar methods used by Davidson and Romanach (2007) Groom, (2009) in Save Valley Conservancy and Groom et al., (2017) in Gonarezhou National Park. Four methods (informed guess, secondary data, spoor count and individual identification), were used. 
Secondary data was collected from patrol reports done from January 2018 to December 2019, informed guess through oral interviews with three local Professional hunters and three SWRA park Managers who had expert knowledge on carnivore surveys were carried out from $1^{\text {st }}$ to $10^{\text {th }}$ April, 2020, to identify known range areas and estimate big cats in SWRA. Spoor track counts and individual observations along twelve transects from $13^{\text {th }}$ to $20^{\text {th }}$ April 2020 was done in known big cat range areas. Twelve transects were considered adequate to cover a bigger area and increase sampling intensity. In selecting transects, two assumptions were made (a) big cats in SWRA were territorial and use of transects walks along known range areas would yield better results and, (b) Big cats distribution is influenced by surface water, terrain and prey availability. Use of transects walks were preferred due to their precision and ability for observers to intensively scan spoors along transect. In this design, it was assumed data collection within one week would yield better results since the area is not confined and large cats can move to adjacent areas while others can move into the study area.

\section{Oral interviews}

Oral interviews with three local professional hunters and three SWRA Park Managers were carried out to have an overall insight on population size estimate through informed guess and to establish known range areas where big cats are mostly sighted during setting hunting baits. The participants were asked to provide detailed information on their encounter with big cats, areas and number of animals sighted for the past six month. The participants were also asked to provide any data and photos available which was collected during the sightings. Information was captured in a notebook and all areas mentioned were regarded as range areas. Potential range areas were also mentioned.

\section{Patrol data (Secondary data)}

Patrol data from January 2018 to March 2020 from reports were retrieved from station patrol records. Species sighted, number recorded and GPS coordinates were captured. Where sex and age of sex of the species was given, it was also captured into excel. Data were summarised to indicate GPS coordinates of big cat sightings done during patrols for the period.

\section{Spoor survey and individual identification}

Twelve transects of varying length ranging from $4.5 \mathrm{~km}$ to $6 \mathrm{~km}$ with a mean length of $5 \mathrm{~km}$, with some running parallel to major rivers, covering different habitats and terrain and in known big cats range areas were purposively set to cut across animal tracks heading to water and feeding sites. Six groups of field observers each consisting of two-man were recruited based on their previous experience in spoor counts, trained for two days, then deployed into marked transect areas to carry out the survey. Spoor surveys and individual observation on live sightings along selected transects where done concurrently recording data on group size, GPS coordinates and general area only. Data collection lasted for four days and survey team walking along transect from the $13^{\text {th }}$ to $14^{\text {th }}$ April 2020 and from the $19^{\text {th }}$ to $20^{\text {th }}$ April 2020. Standardised time- based on same starting and end-time-area count for all groups for spoor and direct observations were done, from $0600 \mathrm{hrs}$ to $0900 \mathrm{hrs}$ in the morning and later afternoon from $1500 \mathrm{hrs}$ to $1800 \mathrm{hrs}$. Spoors of less than twelve hours and individual observations of big cats were observed and recorded. 


\section{Data Analysis}

In this study, only secondary data was manipulated through triangulation of sightings data from same general area into one taking into account number of species recorded, season and frequency of recordings of a single animal/ groups. This was done to minimise double entry of same individual or group of each species.

Triangulation of data from different methods and different sources was done for big cats. Data from transect survey on spoor counts and individual observations were captured, sorted and summarised in Microsoft Excel 2013 to estimate big cats population status. Response from oral interviews on educated guess on population estimate done with local Professional Hunters and Park Managers were analysed using descriptive method. GPS coordinates from patrol reports were imported in QGIS to establish spatial distribution of big cats. G.P.S coordinates from transect surveys and obtained from patrol reports were fed into QGIS 3.12.0 software and projected using World Geodetic system (WGS) 84 and subsequence analysis were performed to map spatial distribution of big cats in SWRA. Spatial distribution maps from spoor survey and from patrol reports data were generated separately.

\section{RESULTS}

Results obtained from each method used in this study were presented separately (Table 1) Total survey area was $343 \mathrm{~km}^{2}$ and estimated spoor density from spoor survey was 0.21 and 0.05 for leopards and lions respectively representing 6 leopards $/ 100 \mathrm{~km}^{2}$ and 1 lion per $100 \mathrm{~km}^{2}$. Recorded pride size basing on spoor sighting and secondary data in lions varied from one to four (Mean =2 \pm 1 ) and in leopard was between one and two (Mean =2 \pm 1 ) for spoor and individual sightings. For spoor and individual identification, total distance of $240 \mathrm{~km}$ were walked, representing a penetration ratio of 1: 1.43 (total number of $\mathrm{km}$ walked to total sample area).

Table 1: Summary of big cat population estimates from each method.

\begin{tabular}{lcll}
\hline Criteria used & $\begin{array}{c}\text { Methods of data } \\
\text { collection }\end{array}$ & Lions & Leopards \\
\hline${ }^{1}$ Informed guess & 1 & 7 & 13 \\
${ }^{2}$ Secondary data & 2 & 9 & 17 \\
Spoor counts & 3 & 5 & 21 \\
Individual identification & 4 & 0 & 2 \\
\hline
\end{tabular}

(Source: Field survey, interviews and patrol data, 2020)

\footnotetext{
${ }^{1}$ Informed guess figures were averaged from 3 resident Professional Hunters and three SWRA Park Managers.

${ }^{2}$ Secondary data were used to estimate population size based on previous individual sightings and areas.
} 


\section{Spatial distribution of big cats in SWRA}

Spatial distribution of big cats in SWRA based on patrol reports data and from spoor survey in SWRA are shown on maps below (Figure. 2 and 3). GPS coordinates captured during patrols were used to map distribution.

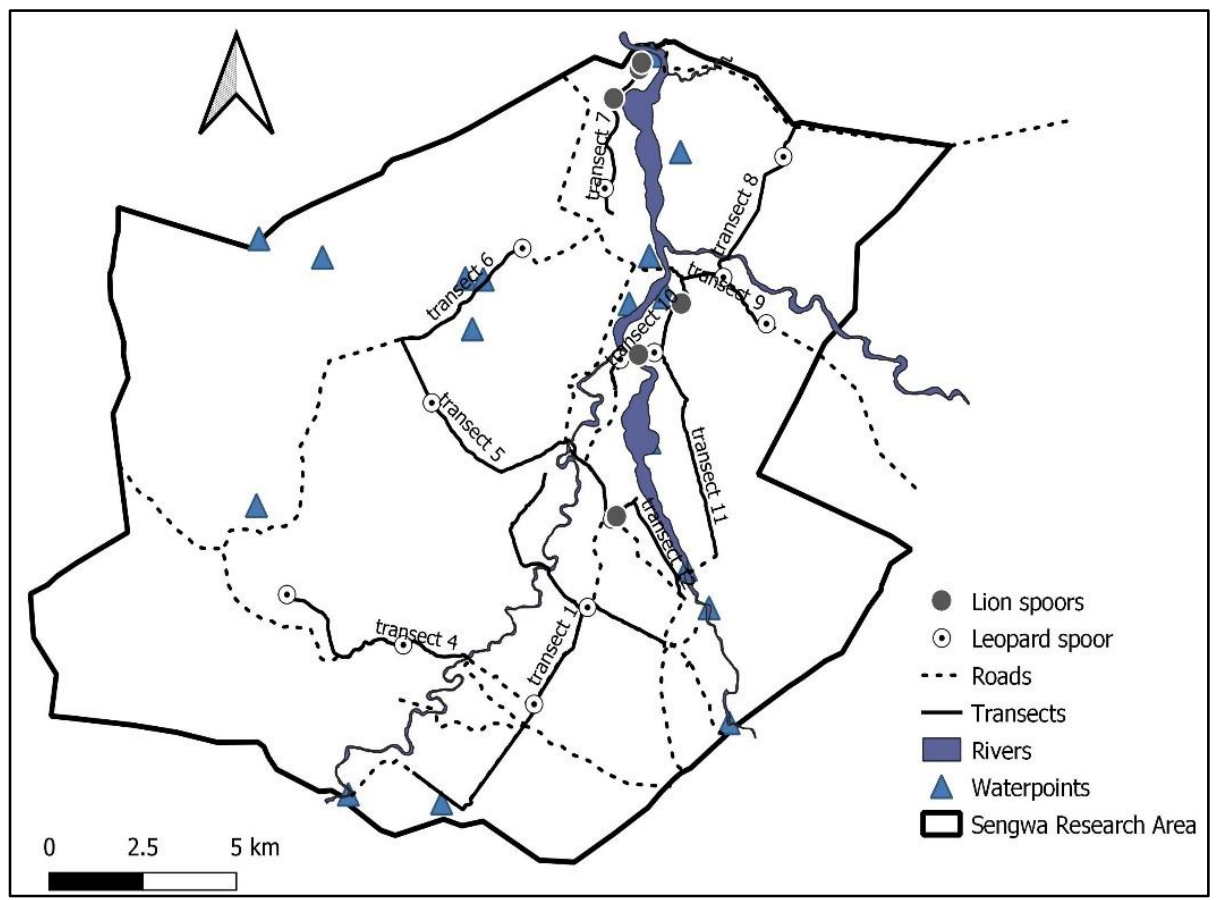

Figure 2: Map showing distribution of big cats in SWRA based on spoor survey.

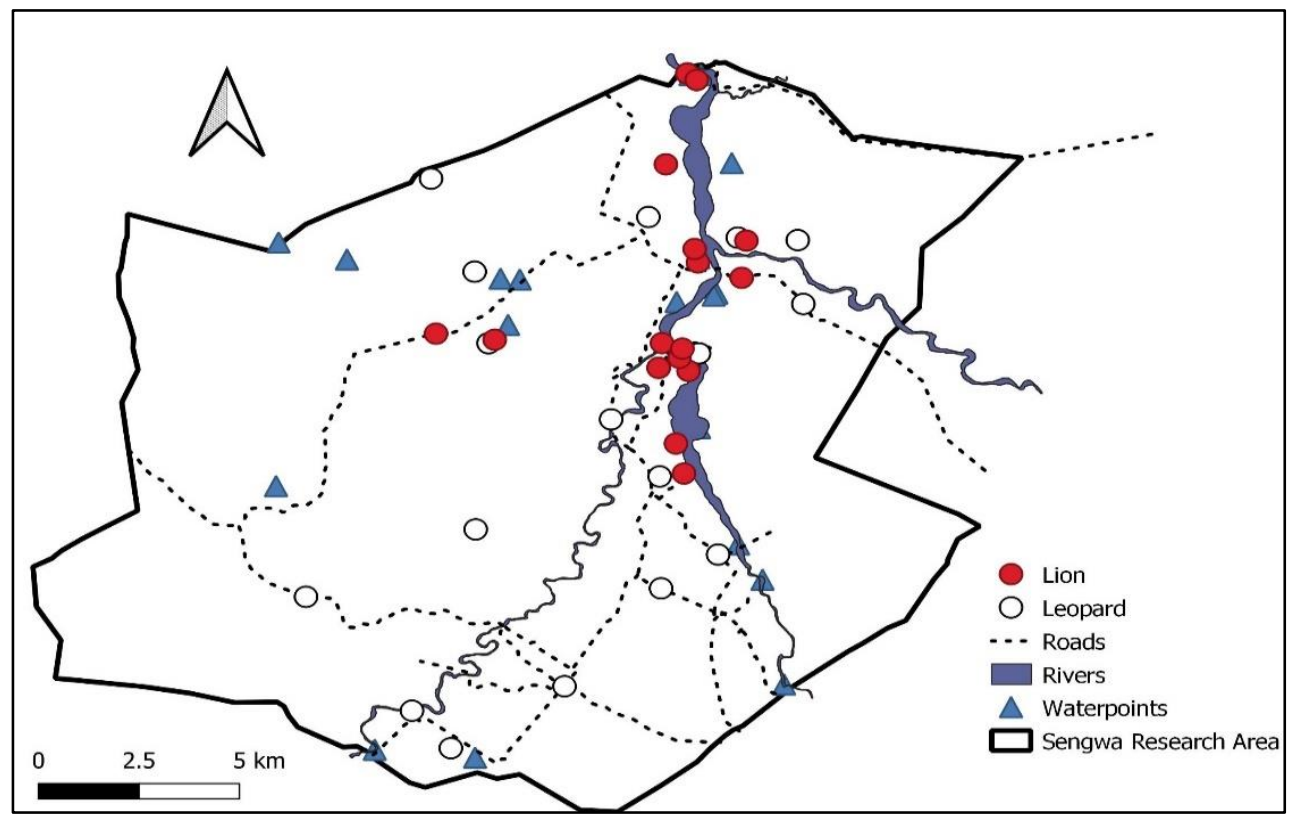

Figure 3: Map showing distribution of big cats in SWRA based on patrol reports. 


\section{DISCUSSION}

From the study, results obtained from each method varied. Results from the survey for leopards alone in SWRA using spoor counts indicated a higher number compared to 2019 National Leopard camera trap survey which only covered the northern boundary. More spoors of lions were sighted during the 2020 survey, to those recorded during 2019 National Leopard Survey. The 2019 National Leopard survey reported four leopards captured on camera traps with only two encounters of spoors recorded. There was marginal difference between informed guess results and the other three methods used to estimating big cats populations in SWRA in the 2020 survey. It is also possible that spoor counts and secondary data underestimated the population size of the big cats attributed to some spoors not seen in a pride or in hard ground. The estimate of population size of big cats may have been influenced by survey coverage (Loveridge et al., 2019) considering transects surveyed were concentrated in potential and known big cats range areas only.

Although it is believed that lion population in SWRA comprised of territorial prides composed of more than one lioness and cubs, secondary data indicated presence of nomadic adult male lion between Chirisa Safari Area and SWRA since there were movements recorded between the two PAs. Big cats movement among PAs is most likely in search for prey (Dickman, 2004). Lions in SWRA may also disperse from Gokwe South Campfire area as well into Chirisa Safari Area of because there is no physical barriers. However, leopards are believed to be territorial and in most cases solitary except even though some recordings of leopards in pairs or mother with young were recorded during spoor counts and from patrol reports.

Lion spoors were mostly recorded along Sengwa riverine with highest recordings around Sengwa Confluence and Matekenya Vleis. This may be attributed to high prey concentration, surface water availability, suitable hunting habitats and cover for resting during hot days. Resource driven can be the main factor influencing big cats concentration along the river valleys and not competitor driven (Maputla. et al 2015). High concentration of common herbivores such as impalas, buffaloes, waterbuck and zebras occur along the riverine area. Leopards were also recorded along Sengwa and Lutope Rivers and in water source areas such as Ketsanga, Siamulambo and Chenzembwe Sechikole spring as well in mountainous areas of Samapakwa and Hilltop-4. For leopards, the geographic success in SWRA can largely be attributed to its high levels of habitat tolerance and had been observed to be most in woodlands and grassland savannahs. Leopard distribution patterns can also be affected by interspecific competition in SWRA and elsewhere with sympatric carnivores such as lions (Carter et al., 2015). Leopards have been known to adopt to various strategies to coexist with lions, including alternate activity patterns (Durant, 2002) and prey specialisation (Donadio and Bushirts, 2006) and arboreal catching of prey in which records from patrol reports indicated some animals hanged in trees from leopard kills. Leopards have a large variety food sources which ranges from birds, plants and herbivores among others.

Spatial distribution of big cats in SWRA should be viewed with caution considering that some water points dry up around June and seasonal movement of their prey, as they are mostly affected by prey availability and season. When some seasonal water points dries up, most herbivores migrate to floodplains of Sengwa, Manyoni and Lutope Rivers as well occupying tracts of vleis in the Sengwa area until the first rains which fill up the water source. Big cats hunting in Sengwa had been successful a couple of years ago. Targeting of old lion males by hunters in previous years could also have resulted in lions migrating to Chizarira National Park 
to seek refuge where hunting is not taking. Hunting may also reduce chances of sightings during daytime. Such is also a case with leopards which are mostly solitary and very active during the night thus difficult to encounter them during the day. In this survey, four methods were used (informed guess, secondary data from patrol reports, spoor counts and individual identification) in order to improve estimating abundance and distribution of big cats in Sengwa.

\section{Strength and weakness of method used in data collection.}

Strength and weakness of methods used based on how they were applied during data collection varied from one method to another. However, data obtained from spoor counts and patrol reports demonstrated ability to show exact areas and to map big cats distribution in SWRA. Use of multiple conventional methods to come up with better estimates where resources are not adequate can be better when new technology such as use of camera traps and drones is still limited.

\section{(i) Informed guess}

In this survey, the use of informed guess was found to be the best starting point if data is required quickly and less resources are needed. This method can be applied off-field without going out for data collection. Data was collected based on participant's previous encounters and experience with the area. The participants gave data on individual identification or use of spoors encountered during tourism activities and patrols. Information supplied helped to have a clue on known and potential range areas for big cats in Sengwa. However during interviews it was noted the method cannot be used to estimate size of the home range nor does it give the actual position where the big cats were found. However, method was supported by use of data from camera traps, safari photos, and data obtained from baits which were taken during hunting activities.

Use of experienced professional hunters and guides who know the area well and tourists gives the data reliability. This method is of limited use if participant provide data from only covered areas, however, enough coverage by professional hunter may yield representative data for Sengwa Area. The method was likely to overestimate big cats population size considering some of the participants has interests in the hunting industry. Information supplied can be exaggerated to facilitate more quota hence data need to be authenticated with scientific verification. Another disadvantage of the method which was observed is it's not suitable where big cats moved into new ranges or hard already moved out of the previously known ranges. Territories based on previous observations may not reflect the current habitat use.

\section{(ii) Secondary data}

One greatest disadvantage of using data from patrol records noted during the survey was data was collected for other purpose. However, data had potential to establish habitat utilisation and spatial pattern basing on signs, individual observation and spoor counts and sounds. Where individual sightings were made, detailed information on sex and age were recorded during patrols. The method was considered cheaper and data was collected while monitoring illegal activities in the patrolled areas. In recent years, it was noted data obtained from secondary reports was used widely in annual reports where estimates are based on data obtained from patrol reports. Where patrol coverage and other biological monitoring activities are effective, the method was considered to be representative of the whole SWRA. Using the methods, number of prides in lions in an area can easily be established. 
Triangulation of reports from different patrol teams was found to be possible and population estimates can be done after a certain period. However, the data obtained from the methods showed multiple recording of a single group of species and in lion's variation in number was likely since lions can move in a group but at distant from each other resulting in some individuals or spoors not seen hence missed in recording. Secondary data from camera traps obtained during hunting in Sengwa and pictures from field rangers, supplied good data for example species presence, sex, habitat utilisation and behaviour. Secondary data for big cats were obtained from patrol reports, pictures done during patrols, signs from observed kill sites, as a result it was difficult to differentiate how data was recorded and from which sign compromising consistent on data collection method, source and type of information to be recorded. The method can be easily integrated into new technology hence data can be collected using Spatial Monitoring and Reporting Tool (SMART) during patrols and later imported for analysis in a computer.

\section{(iii) Spoor counts}

The use of spoor counts was difficult in hard clay soils and rocky area along Samapakwa ridge and sandy soils along the Sengwa riverine and Road 33 and Confluence Road hence the method was subject to underestimating and sometimes repetition of spoors counted in some areas. During the survey, age estimation using spoors was very difficult to differentiate for subadult bulls from adult females as well in juveniles. The spoors looks almost similar. Time spend collecting data was only one week giving the method limited time needed and suitable for small areas such as SWRA. However, the method can be very difficult in complex ecosystems such as the whole Sebungwe region where nomadic cats occur. In Sengwa, method was observed cheaper to apply where ecologists don't have resources compared to modern technologies such as the use of drones and camera traps. The method does not need approval and is free to use unlike drones. Elsewhere the method had been widely used in Gonarezhou and save valley and yielded good results in estimating abundance and distribution in cryptic and nocturnal species such as big cats. Using a single census, however, one disadvantage is that it was noted the method can be difficult to establish actual number of groups and if group sizes are large in an area and where transects being used are not evenly terrain distributed and not representative if not properly stratified. Best results were obtained during early morning recordings, however, other animal movements were observed to disturb the big cat's spoors through their movements once sunrise.

\section{(iv) Individual observation.}

In Sengwa, individual sightings were very difficult and this was attributed to hunting practise since the big cats are in most cases the targets and maybe because they are nocturnal carnivores. The animals shy away from vehicles and hunters and this may compromise the survey. However, using camera traps in combination with baits, lions and leopards were easily identified coming to the bait at night-time. In terrain and inaccessible areas, leopards are difficult to sight and they are able to first observe approaching enemies from a distant and escape into crevices and there other hiding places. Detailed information on sex, age and exact area were recorded by observers where sightings were done. In closed area, sightings were observed to be very poor and difficult. The method can also be affected by time of day. However, the results could have also influenced by many factors including time of survey and terrain as also highlighted by Loveridge et al, (2019) in some PAs of Zimbabwe. Lions and leopards are nocturnal hence, can only be sighted early in the morning as well later evening 
when they become active. In some places data verification can be done through GPS coordinates and photos. Where big cats avoid open grounds and utilise ridges such as Ntabamangwe and Samapakwa, it was difficult to identify come across the species.

\section{Data triangulation}

Cats are notoriously hard to observe. Many species are shy, solitary and nocturnal with wide ranging patterns and naturally low densities, limiting efforts to obtain reliable population estimate using a single method. Triangulation of method and data for big cats in SWRA were used to address weakness of each of the four methods employed in this survey. Spoor count were more reliable and appropriate method for nocturnal animals which are difficult to encounter (Waterrmeyer, 2017). Spoor counts for example gave an indication of precision but not necessarily of exactitude whereas direct observation shows exactitude or underestimates. This use of spoor counts had been used elsewhere including in Gonarezhou and Save Valley Conservancy (Groom and Waterrmeyer, 2017; Davidson and Romanach, 2007; Groom, 2009). Use of spoor survey and oral interviews in estimating big cats population and distribution in SWRA was considered cheaper and more accurate and lack of hard data on population numbers can often be compensated for by optimistic guesstimates from wildlife practitioners in respective PAs (Trouwborst, et al 2019). A combination of interviews, patrol reports and spoor surveys have been used with some success to measure animal distribution, and animal abundance, of different species of Canidae (Allen and Sargeant, 1975; Harris, 1981; Clark and Andrews, 1982; Fanshawe et al., 1997). Interviews were successfully used in Senegal to detect the presence of elusive carnivores (Kane, 2014).

\section{Implication to Research and Practice}

Many agencies compile status reports using data collected from any of the methods used in this survey to access the relative abundance and distribution of carnivores, particularly in countries that are unable to invest the considerable resources for more accurate population assessment (Fanshawe et al., 1997). Integration of multiple methods greatly increased researcher understanding on big cats abundance and distribution in SWRA over which management decisions can be made. It was however observed during survey that methods were difficult to use in estimating actual home range sizes in SWRA since this requires several sightings and recording of data from points. All methods used reflects good indicators of how big cats are distributed in SWRA and this can easily be related to other factors such as surface water and prey availability.

\section{CONCLUSION}

In sum, data obtained from each method suggest marginal variation in big cat population in SWRA with lions mostly recorded along the river valleys whilst leopards seemed to occupy all terrains and different habitats. Of course, all of the selected methods come with their obvious trade-offs and challenges. Triangulation of data sources and methods demonstrate that if applied correctly, estimating abundance and distribution of cryptic carnivore species can help come up with proper estimate. All methods used for this study demonstrate a quick way of determining presence or absence of big cats in SWRA and can be applied in any PA. 


\section{Future Research}

Possible future related researches in monitoring abundance and distribution of big cats in SWRA are recommended using sight specific survey method such as integrating conventional and new technology such as use of camera traps in conjunction with baits and spoor survey. The study also recommend comparison on the use of conventional and new technology such as radio call ups, camera traps and use of GPS enabled collars in order to develop a more robust technic for big cats abundance and distribution estimate in SWRA. It is also recommended to expand the survey of big cats to cover Sebungwe complex.

\section{Acknowledgement}

I wish to dedicate this paper to SWRI Rangers for their assistance in data collection. I am grateful to the Zimbabwe Parks and Wildlife Management Authority Chief Ecologist Mrs. R. Mandisodza-Chikerema for supporting this study. I thank the Local Professional Hunters and Park Managers for their overwhelming support during the oral interviews. Comments and suggestions by an anonymous reviewer are also greatly appreciated.

\section{REFERENCE}

Bauer, H., Kari, S. (2001). Assessment of the people-predator conflict through thematic PRA in the surroundings of Waza National Park, Cameroon. Participatory Learning and Action Notes, 41, 9-13

Chardonnet, Philippe. (2002). Conservation of the African Lion: Contribution to a Status Survey. International Foundation for the Conservation of Wildlife, Paris.

Chikerema-Mandisodza, R., Groom J. R. (2012). Preliminary non-detriment finding assessment preliminary report for leopards in Zimbabwe December 2012.

Davidson, Z., Romanach, S. (2007). Estimations of lion and hyena density in the Savé Valley Conservancy using two different census techniques: spoor transects and call-up stations. Report for SVC, Wild CRU and University of Zimbabwe, TREP.

Donadio, E., Buskirk, S.W., (2006). Diet, morphology, and interspecific killing in Carnivora. The American Naturalist, 167(4) 524-536

Durant, S.M. (2000). Living with the enemy: avoidance of hyenas and lions by cheetahs in the Serengeti. Behavioural Ecology, 11(6) 624-632

Ferreira, S., Funston, P.J. (2010). Estimating lion population variables: prey and disease effects in Kruger National Park, South Africa. Wildlife Research 37(3).

Ferreras, P. and Cousins, S. H. (1996). The use of a Delphi technique with GIS for estimating the global abundance of top predators: International EcoTechnology Research Centre, Cranfield University, UK.

Groom, R. J. (2010). Carnivore densities in the Savé Valley Conservancy; Results of the 2010 spoor survey. Report for Savé Valley Conservancy Technical Advisory Committee.

Groom, R. J., Waterrmeyer, J. (2017). Carnivore Densities in Gonarezhou National Park Results of the 2017 Spoor Survey.

Groom, R.J. (2009). Carnivore densities in the Savé Valley Conservancy; Results of the 2009 spoor survey. Report for Savé Valley Conservancy Technical Advisory Committee. 
Henschel, P., Hunter, L., Breitenmoser, U., Purchase, N., Packer, C., Khorozyan, I., Bauer, H., Marker, L., Sogbohossou, E., Breitenmoser-Wursten, C. (2008). Panthera pardus. IUCN.

Internal Union on Conservation of Nature. (2018). Guidelines for the conservation of lions in Africa (I. S. C. S. Group, Ed.). Species Survival Commission.

Jackson P., Kristin, N. (1996). Wild cats: status survey and conservation action plan. IUCN, editor. Gland, Switzerland: IUCN/SSC Cat Specialist Group. 382.

Lindsey, P.L., Balme, G.A., Booth, V.R., Midlane, N. (2012). The significance of African lions for the financial viability of trophy hunting and the maintenance of wild land.

Loveridge, A. J. (2002). Hwange Lion Project. Workshop on Ecological Research in Hwange National Park. Wildlife Conservation Unit, Oxford.

Loveridge, A.J., Searle, A.W., Murindagomo, F. Macdonald, D.W. (2006). The impact of sport hunting on the population dynamics of an African lion in a protected area. Journal of Science Direct.

Loveridge, A.J., Seymour-Smith, J.L, Sibanda, A. (2019). Interim report on large predator camera trap surveys in western and northern Zimbabwe. Unpublished report to the Zimbabwe Parks and Wildlife Management Authority.

Marker, L.L., Dickman, A.J. (2004). Factors affecting leopard (Panthera pardus) spatial ecology, with reference to Namibia's farmlands. Journal of Wildlife Research, 35 (2).

Merwe, V.D., Bauer, H. (2004). Inventory of free ranging lions in Africa. Oryx, 1(38), 2631.

Monks, N. (2005). Lion management plan: Zimbabwe: Research and management needs. Presentation at the Workshop to develop a conservation strategy and action plan for the lion in Zimbabwe. Harare.

Nakedi, W., Nkabeng T.M., Christian T.M., Chimimba, S., Ferreira, M. (2015). Spatiotemporal separation between lions and leopards in the Kruger National Park and the Timbavati Private Nature Reserve, South Africa. Global Ecology and Conservation, 3, 693-706.

Neil Cartera, N., Micah Jasny, M., Gurung, B., Lau, J. (2015). Impacts of people and tigers on leopard spatiotemporal activity patterns in a global biodiversity hotspot. Global Ecology and Conservation, 3, 149-162.

Nicholas, B Elliot Arjun M Gopalaswamy (2017). Toward accurate and precise estimates of lion density. Conservation Biology, 31(4):934-943.

Purchase, G. (2002). Aspects of the ecology and behaviour of lions (Panthera leo) and spotted hyenas (Crocuta crocuta) in Matusadona National Park. University of Aberdeen.

Trouwborst, A., Loveridge, A.J., Macdonald, D.W. (2019). Spotty Data: Managing International Leopard (Panthera pardus) Trophy Hunting Quotas Amidst Uncertainty. Journal of Environmental Law, 1-26.

Woodroffe, R., Frank, L. G. (2005). Lethal control of African lions (Panthera leo): local and regional population impacts. Animal Conservation, 8, 91-98.

Zimbabwe Parks and Wildlife Management Authority (2016). Status of lion (Panthera leo) in Zimbabwe-ZPWMA Scientific Services Unit 